vention, but there are also going to be babies who die because of interventions," she explains. "There's no way to ensure a successful birth every time. Sometimes a baby dies and that's just the way it is."

It's not a stance Shanley takes lightly, having lost a child to a congenital heart defect following an unassisted delivery, and been told by a coroner that the baby would have died even if she had gone to the hospital.

It's a difficult stance to counter, says Canadian Association of Midwives President Anne Wilson. "You can't say to a mum that $60 \%$ of all unassisted births result in complications where the baby dies because that kind of statistic doesn't exist. A lot of complications in childbirth are predictable and occur over time, but a few happen without warning, such as severe hemorrhage.
And if a woman doesn't have prenatal care, doesn't report the birth to the hospital, there's no way to know."

Globally, over 500000 women die each year from complications during childbirth, according to the Society of Obstetricians and Gynaecologists of Canada.

"Unassisted childbirth is unsafe period," said past vice president Dr. Vyta Senikas in the statement on freebirth. "The people advocating this as a mainstream option for women are tragically uninformed."

Midwives, however, are more "fuzzy" on the issue, says Wilson. The association has yet to take an official stance for fear of alienating women wary of intervention. "If someone came to us who was considering an unassisted birth we would want to keep that person engaged, build a relationship of trust and if they ended up going ahead with it, at least you're someone they can call if they get half way through a delivery and change their mind.'

Failing that, "some prenatal care is better than none," she adds.

The debate raises ethical questions of "autonomy versus beneficence" for midwives, Wilson says. "By the nature of what we do, we tend to look after people who don't want interventions. It would come down to individual choice in terms of how comfortable you are as a practitioner taking that person into your care."

For Shanley, however, unassisted childbirth is more a question of reproductive rights. "It's your body, your birth and your baby, so you should have the right to give birth however you want." - Lauren Vogel, CMAJ

CMAJ 2011. DOI:10.1503/cmaj.109-3820

\title{
Comparison shopping for drugs
}

A Web-based drug comparison tool developed by a nonprofit lobby for Americans over 50 will allow patients to price shop for prescription drugs as they would fridges or cars to ensure they're getting the best bang for their buck.

The Drug Savings Tool is the most recent in a suite of free health tools crafted by AARP (formerly the American Association of Retired Persons) to spark patient-doctor conversations about the cost, safety, efficacy and proper use of prescription drugs.

Developed in partnership with Consumer Reports, the tool lets patients compare the cost and efficacy of a drug to those of its brand name and generic competitors, and recommends a "best buy" based on clinical evidence. Patients can then print that information and share it with their doctor when discussing treatment options.

"Consumers are at a disadvantage in the health care market because they don't have access to credible and easyto-understand comparative information for drugs like they do for traditional products," says Doris Peter, manager of the Consumer Reports Health Ratings Center.

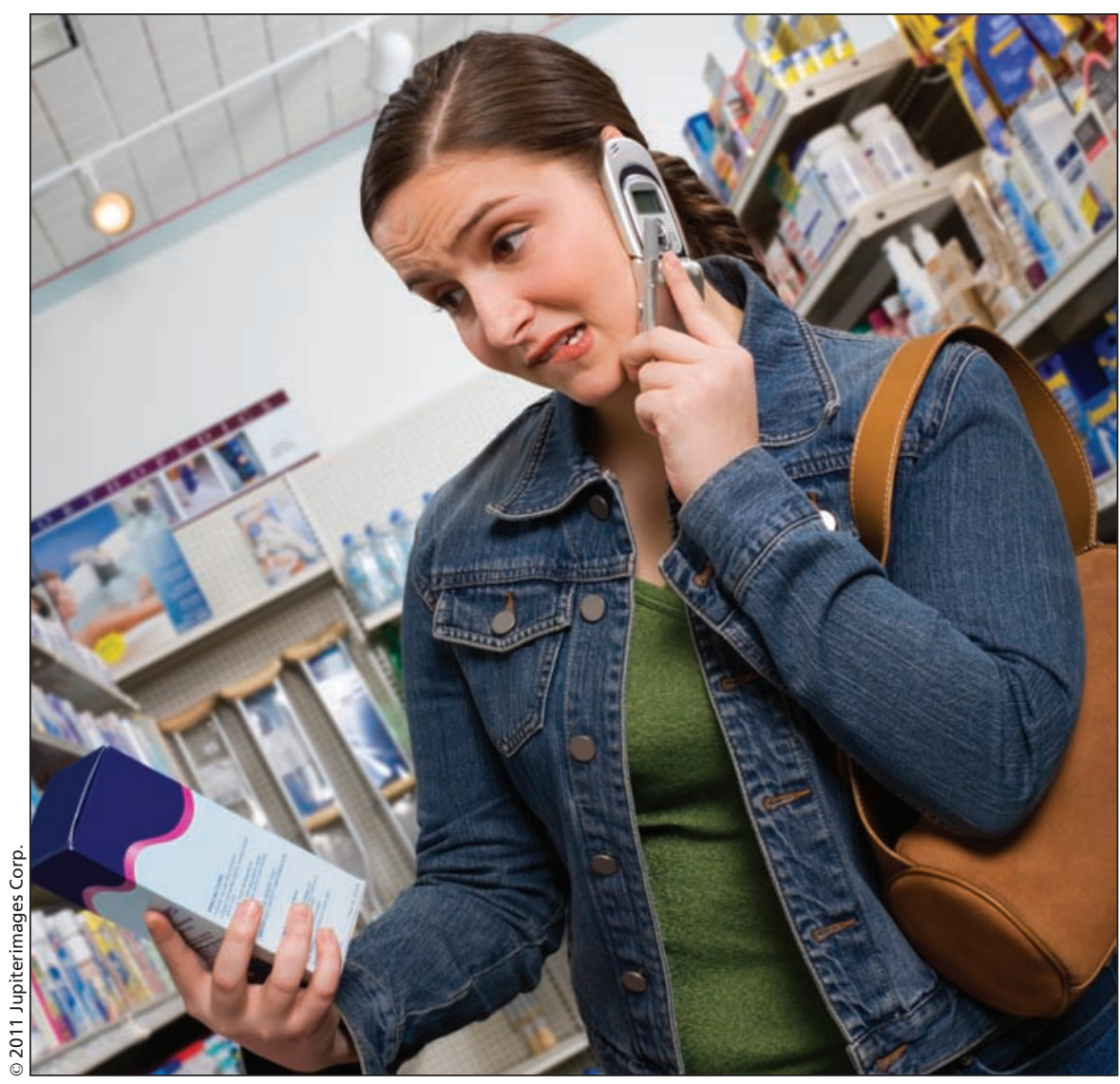

Some experts say that consumers and physicians are at a disadvantage in making drug choices because they don't have access to credible and easily digestible information about drug prices, efficacy and effectiveness. 
Without that unbiased information, or an awareness that alternative treatments exist, it's difficult for patients to join their practitioners in the decisionmaking process, she says. "The information they're currently receiving either comes from direct-to-consumer advertising, which is completely conflicted, or doctors that have as little access to digestible information about price as consumers do."

The price of ignorance is high. It's estimated the average employee in the United States will cough up \$US4386 in 2011 to cover his or her health care insurance premiums and out-of-pocket costs such as copayments and deductibles (www.cmaj.ca/cgi/doi/10.1503/cmaj .109-3713).

"Even if you have coverage, it will often come in levels or tiers, so the brand new version of a medication is going to cost you a lot more because you might have a higher copay or it might not be on your formulary," says Cheryl Matheis, senior vice president of health strategy for AARP. "We've done polls looking at the effect of the economic downturn on our members and found that people are skipping buying necessities so they can afford their medications, and vice versa. They're splitting pills, skipping doses, and even sharing prescriptions with friends."

Now, rather than "blindly paying out of pocket," price-conscious consumers can "compare the alternatives online, print out the information in a simple format and discuss their options with a doctor," she says.

While patients have turned to Google in search of such information in the past, the tool is the first to provide comprehensive, evidence-based comparisons and recommendations in a user-friendly format.

The site is designed with an older, less tech-savvy audience in mind, Matheis says. "Our membership are people aged 50 and older, and while that's the fastest growing group of Internet users, we had to make something that would be easy to understand and could be accessed in more than one way. For instance, when you're searching for a medication, you can type in the name of the drug or, if you don't know how to spell it, you can search an alphabetical list."

Information on the site is layered to prevent users from feeling overwhelmed, she says. The initial search result for a drug will turn up a printable comparison sheet detailing the cost and efficacy of various alternatives, but users can also click through for additional information about drug safety and interactions.

The Drug Savings Tool is just one of several interactive health tools on the site, including a drug interaction tool and a pill identifier. Each tool is designed to overlap others in content so that users can access information on the site in a variety of formats and from a variety of entry points.

AARP is also in the process of building a health insurance comparison tool for release later this year. Lauren Vogel, CMAJ

CMAJ 2011. DOI:10.1503/cmaj.109-3828

\section{More news at www.cmaj.ca}

\begin{abstract}
Bringing palliative care to the homeless: The best means of providing palliative care to the homeless, experts say, is to bring the services to the place they feel most comfortable: homeless shelters. Roger Collier, CMAJ
\end{abstract}

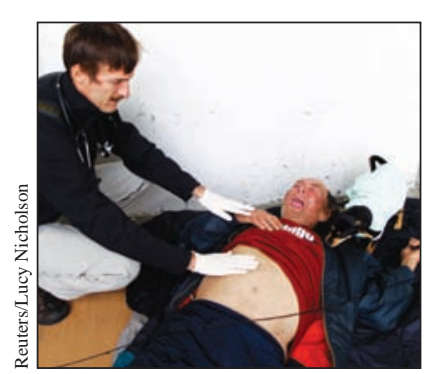

Better home care and better pay for doctors urged at CMA town hall: The Canadian Medical Association's "adult conversation" on health care transformation again elicited calls to create a national pharmacare program and greatly expand home care. - Paul Christopher Webster, Toronto, Ont.

Scent-free policies generally unjustified: The science supporting scent-free or scent-reduction policies is fuzzy and inconclusive. - Emily Senger, Toronto, Ont.

Europe contemplates stricter language proficiency testing of doctors: European nations may be creeping toward the imposition of tougher language proficiency requirements for doctors who'd like to hang up a shin- gle anywhere but their homeland. - Tiago Villanueva MD, Lisbon, Portugal

Oil, water and health care - a difficult mix: Water is among the many challenges that bedevils the only hospital in the Ahanta West district of Ghana. It now must provide care for the massive influx

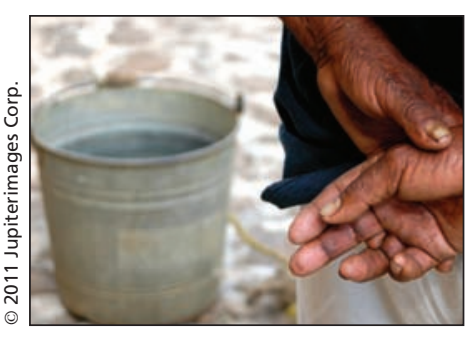
of workers and investors in the booming oil industry, while handling the potential impacts that the boom may have on local residents, who for years quietly earned their livelihoods primarily from the sea. Bernard Appiah, Accra, Ghana

From bedside to bench and back again: Canadian medical research must become more "patient-oriented" by shrinking the space between the wet-bench and the bedside, according to the Canadian Institutes of Health Research. — Roger Collier, CMAJ

CMAJ 2011. DOI:10.1503/cmaj.109-3834 